\title{
Palpable Masses Domain
}

National Cancer Institute

\section{Source}

National Cancer Institute. Palpable Masses Domain. NCI Thesaurus. Code C95097.

A subject domain utilized for the submission of information encompassing and representing data, vocabulary or records related to palpable masses. 